\title{
THE NDT INVESTIGATIONS CARRY OUT AT THE ARUDJ CATHEDRAL, ARMENIA
}

\author{
S. TONNA ${ }^{1 *}$, M. CUCCHI ${ }^{2}$ AND C. TEDESCHI ${ }^{3}$ \\ ${ }^{1}$ Politecnico di Milano - DAStU Department \\ Piazza Leonardo da Vinci, 32 - 20133 Milano, Italy \\ e-mail: sandra.tonna@polimi.it (*corresponding author) \\ ${ }^{2}$ Politecnico di Milano - LPMsc Laboratory \\ Piazza Leonardo da Vinci, 32 - 20133 Milano, Italy \\ e-mail: marco.cucchi@polimi.it \\ ${ }^{3}$ Politecnico di Milano - D.I.C.A. Department \\ Piazza Leonardo da Vinci, 32 - 20133 Milano, Italy \\ e-mail: cristina.tedeschi@polimi.it
}

Keywords: Historical Structure, Masonry, Monitoring, Non-Destructive Inspection

\begin{abstract}
Arudj Cathedral, Armenia, is an example of early-Christian domed-hall that dates 671-672. A deep structural analysis of the building was developed by Politecnico di Milano, during the $I I^{\circ}$ Level Master for Architects and Archaeologists named "Restoration Training and Support to Local Institutions for the Preservation and Conservation of Armenian Heritage". The preservation project mainly focuses on deepen the knowledge level of the building in relation to the architectonical and structural aspects in order to offer a working method with the aim to propose and teach alternative solutions for static and seismic consolidation.

This paper reports the NDT investigations of the surveys carried out at the Cathedral of Arudj and the results obtained at the laboratory of the Politecnico di Milano.

The NDT investigations were carried out by the Authors and here following are briefly described. Sonic investigations on masonry structures were applied for a qualitative comparison of the walls, based on the variation of the sonic velocity values in the presence of areas with lower density, voids or cavities. The passive thermographic technique was applied to identify the distribution of capillary ascent in masonry structures. In order to offer a longterm verification of the evolution of the crack pattern, after having identify the cracks present on the masonry structures some displacement transducers have been fixed to state their evolution hourly.

Finally, a series of laboratory tests were carried out to determine the main mechanical characteristics of the constituent stone.
\end{abstract}




\section{INTRODUCTION}

This report describes the results obtained with an extensive experimental investigation applying NDTs, in order to evaluate the structural damage, their extension and their causes. As known, a proper preservation project for existing structure starts only after an accurate diagnosis of the state of the art based on: on site survey and laboratory investigation. These operations will deepen the knowledge of the building and held respecting its authenticity through an appropriate choice of intervention techniques. The lack of knowledge on the original materials and structures was frequently the main cause of unsuccessful interventions. Furthermore, as happened in this case study, a further problem was found in those buildings that have already been repaired with unsuccessful techniques. From this state of the art a series of questions arise: What actually caused the failures? How did they develop? How serious were their consequences on the overall response of the building?

In particular this is a common condition in seismic areas where masonry structures are characterized by partial or full reconstruction due the earthquake damage.

In order to fulfil these needs by overcoming the gap between our poor knowledge and the complexity of these structure an experimental on site investigation is required and recommended also by Codes and Standards in several Countries. Non destructive techniques (NDTs) and/or Minor destructive Techniques (MDTs) can be helpful in detecting hidden features (wall texture, internal voids and flaws and characteristics of the wall section) which are so much important to define the structural behaviours under dead loads and environmental

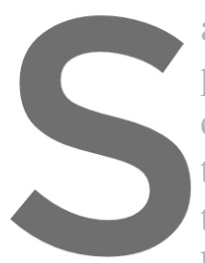
action [1]. It is then problem has to be solve correlation between the they can give an overall qualitative response techniques are represented by the sonic (or ultriso be clear that the responsible of the on site diagnosis must: (i) set up the in-situ and laboratory survey project, (ii) constantly follow the survey, (iii) understand and verify the results, (iv) make

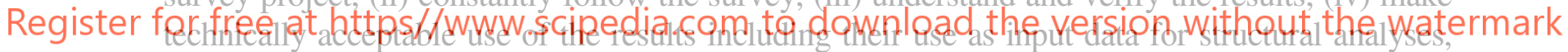
(v) choose appropriate models for the structural analysis, (vi) arrive at a diagnosis at the end of the study [3].

\section{CASE STUDY FRAMEWORK}

The Aruch settlement is located to the west of the Aghbri, a small stream at the southern foot of the Mount Aragats. The urbanization of Aruch dates from a pre-Christian age when a water basin was dug in the bedrock surface, probably with reference to the cult of the spring water. Always belonging to this age, archeological excavations have discovered a large burial ground with approximately 8-12 thousand sepulchres located close to this holy area. After the advent of Christianity the area maintains its religious importance and Aruch became one of the first important Church attested since the early 7 th century A.D.

By the second half of the 7th Century the historical complex took a new more detailed and monumental form, due to the fact that Prince Grigor Mamikonian selected Aruch as the admistrative seat of his government [4]. From this period belong: the costruction of the Catedral and the building located at the south side, as well as the trasforamtion of the previous Church into 
a civil building. The kingdom of Grigor Mamikonian, which coincides with the presence of the Cathilicos Anastas, is described as particulary prosperous for the Aruch site and the city played and maintained an important economic role until the the second half of the $9^{\text {th }}$ century A.D. Nowadays the Cathedral is the only surviving edifice to that golden age.

\section{INVESTIGATIONS CONDUCTED ON MASONRY STRUCTURES}

This report shows the results of the on-site investigations carried out at the Arudj Cathedral and of the laboratory tests conducted at the Politecnico di Milano. On site, non-destructive surveys were conducted on the entire monumental complex, investigating all the structural components: from the foundations to the masonry and roofing structure and for each investigation, the methodology and purposes will be described here following [5].

For the purposes of this article, the results of the tests conducted on a single portion are reported, in order to facilitate the comparative reading of the investigations. The portion under consideration (Fig. 1) was chosen as characteristic of the complex in terms of materials and construction technique, but at the same time, representative of the borderline case as it was seriously damaged by important instability phenomena.

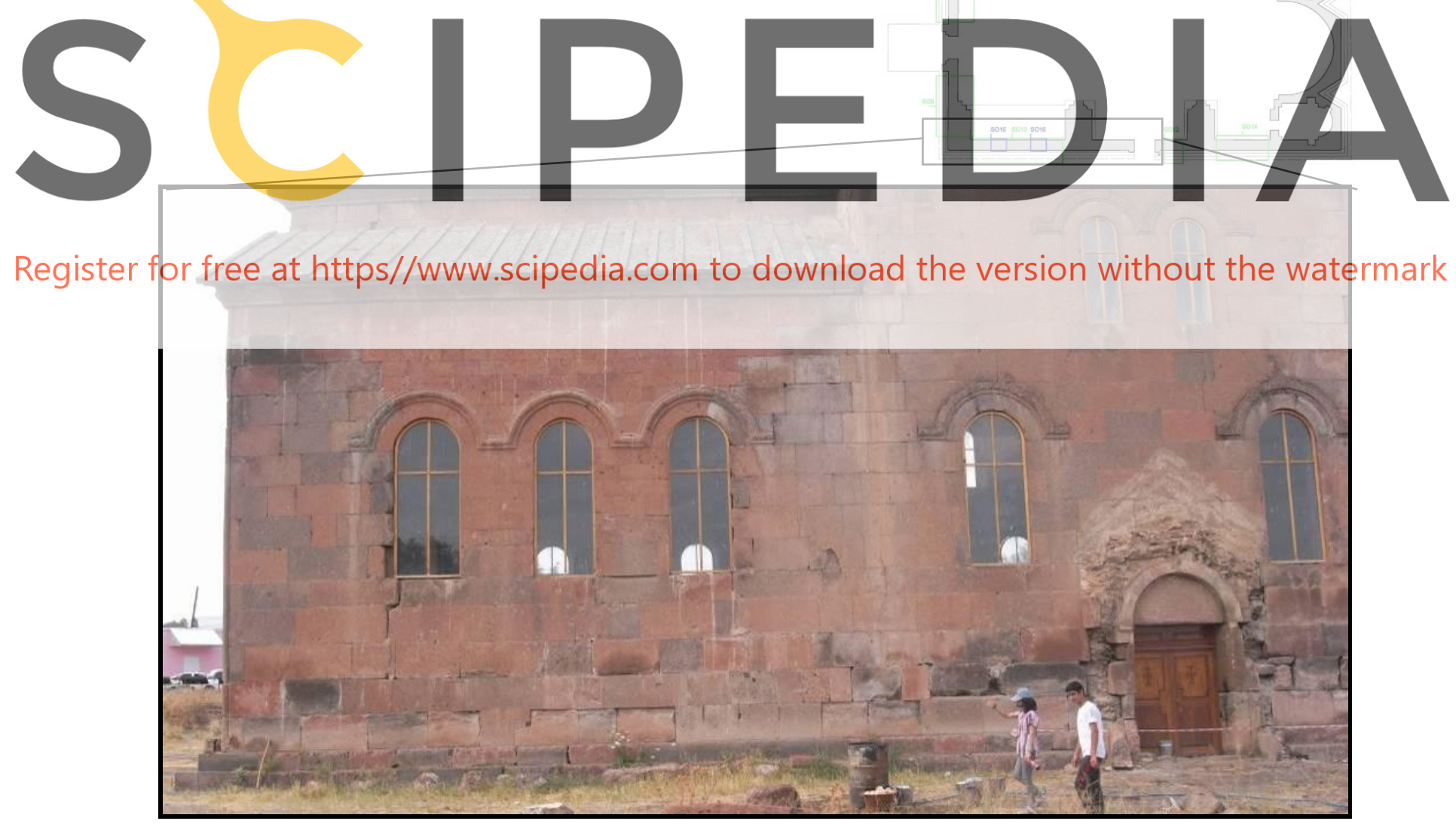

Figure 1: The selected structural portion belonging to the North front 


\subsection{Geometrical and crack pattern survey}

As it known, a well detailed in-situ survey is fundamental to provide informations on the structural geometry and the architeconical elements, in addition, to put the base to identify the points where more accurate observations have to be concentrate. As consequance a more refined investigation has to be carried out, identifying irregularities (vertical deviations, rotations, etc.) and transformations in order to be able to learn them in comparison the historical evolution of the structure. Only throuhg this reading will be possible to explain the signs of damage detected on the building. Following this basic principle an important role has been assumed by the crack patterns survey and drawing (Fig. 2). The interpretation of the crack pattern can be of great help in understanding kinematic mechanism the state of damage of the structure, its possible causes and the type of survey to be performed, provided that the development history of the building is already known [6].
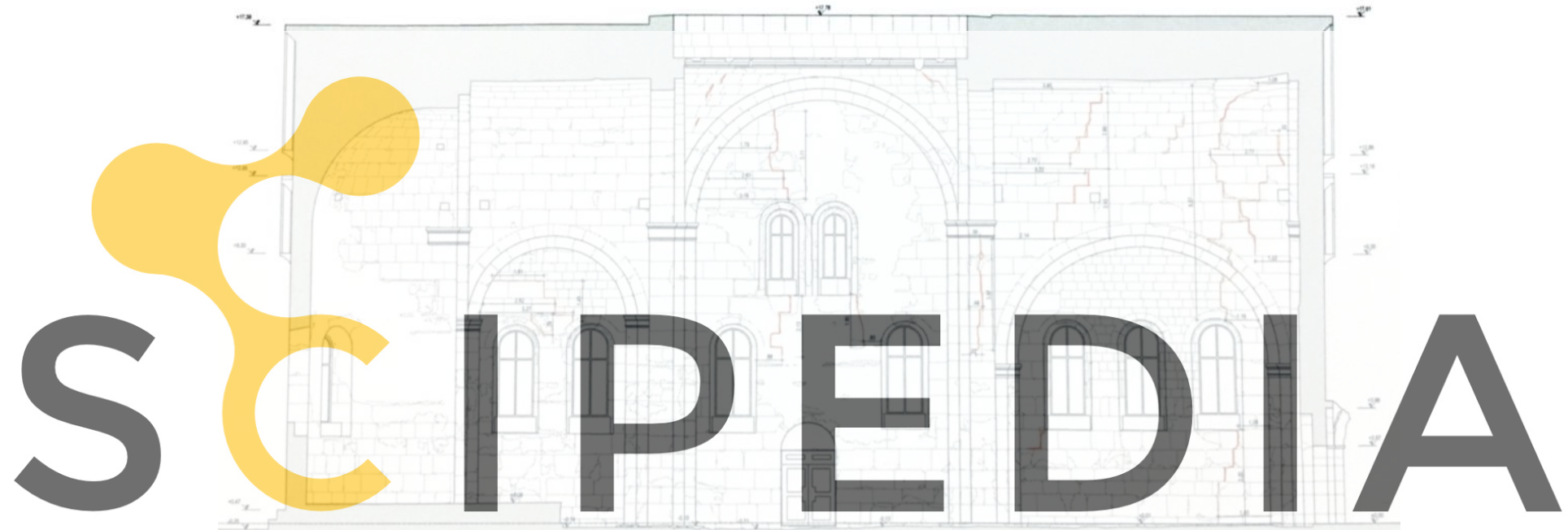

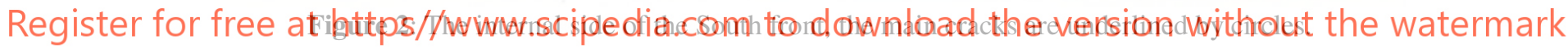

\subsection{Sonic tests}

Among the ND investigation methods, the sonic methods are with no doubt, the most widely used [7]. The testing technique is based on the generation of sonic or ultrasonic impulses at a point of the structure. A signal is generated by a percussion (transmitter) and collected through a receiver which can be placed in various positions. The elaboration of the data consists in measuring the time the impulse takes to cover the distance between the transmitter and the receiver. The use of sonic tests for the evaluation of masonry structures has the following aims: (i) to qualify masonry through the morphology of the wall section, to detect the presence of voids and flaws and to find crack and damage patterns; (ii) to control the effectiveness of repair by injection technique in others which can change the physical characteristics of materials [8]. In agreement with the NDT survey plan, sonic tests have been carried out on the most damaged part of the walls, sixteen areas were detected to analize all the pillars and a large part of the masonry. As requested, the equipment used for the survey is composed by an impact hammer as transmitter, an accelerometer as receiver and by an $\mathrm{d}$ a DAQ board to acquire data. In figure 3, the velocity average recorded in few wall portions is 
visible. In table 1 it is possible to observe the speed differences between the original pillars and those subject to the restoration intervention made with new stones.

Table 1: Example of a sonic test result, here has been selected a survey conducted on a window pillar composed by two different bricks (the original and another type used during a restoration intervention).
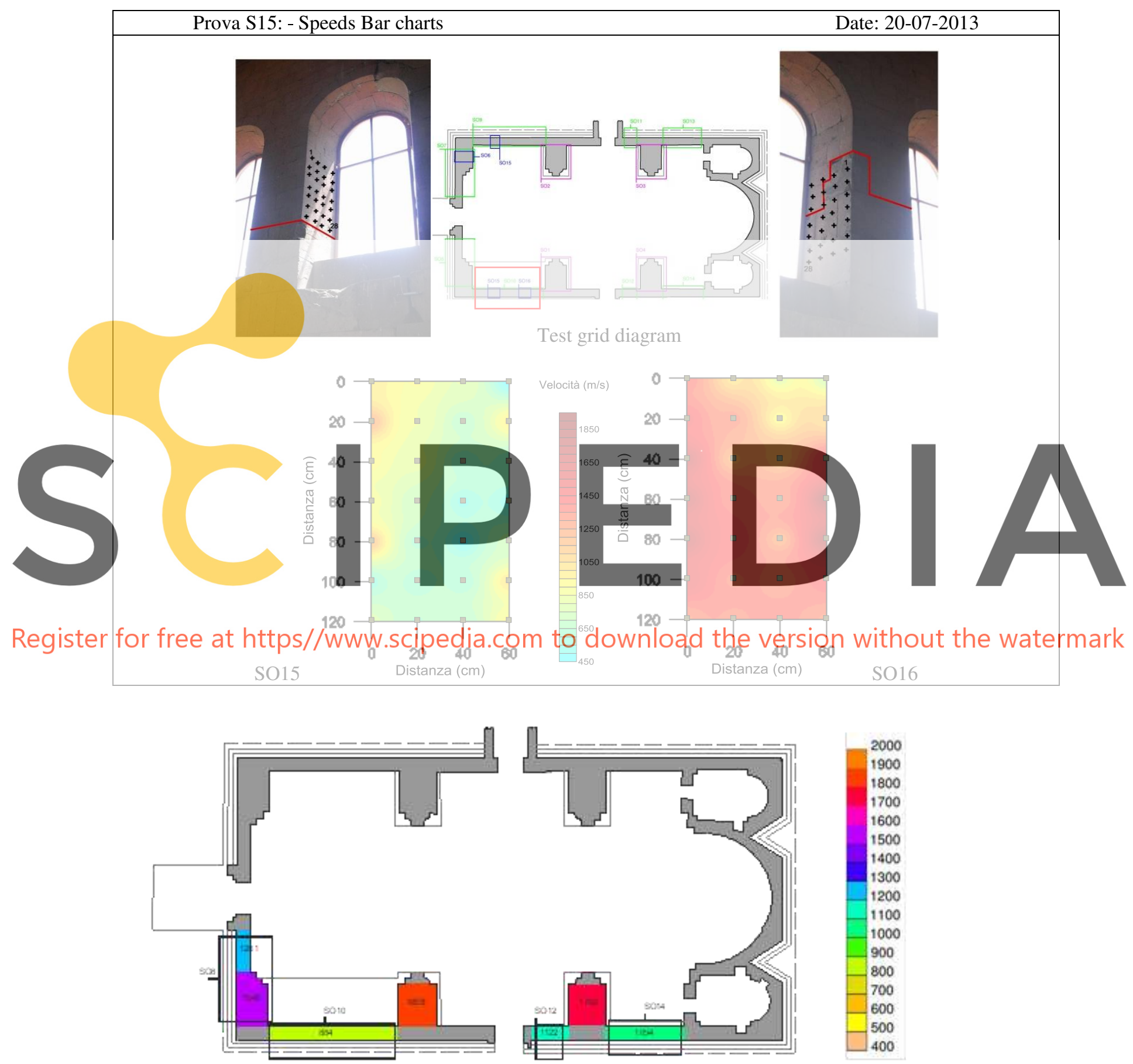

Figure 3: The sonic test investigations, marked in according with the proper color of the corresponding velocity class. At the top right the reference plan with the wall thicknesses 


\subsection{Thermography}

Thermovision is a NDT which has been applied since several years to works of art and monumental buildings. The thermographic survey has the advantage of being applicable to wide surfaces of walls; it is a telemetric method and has high thermal and spatial resolution. Thermovision can be very useful in diagnostic; in fact it is used to identify areas under renderings and plasters that can hide construction anomalies. Other applications can be: (i) survey of cavities, (ii) detection of inclusions of different materials, (iii) detection of water and heating systems, (iv) moisture presence.

Figure 4 shows the presence of moisture and the capillary rise, thanks to the camera which identify the coldest surface areas, where there is continuous evaporation. The evaporation is due to the difference in R.H. between the inside of the masonry and the environment outside and to natural air movements [9].

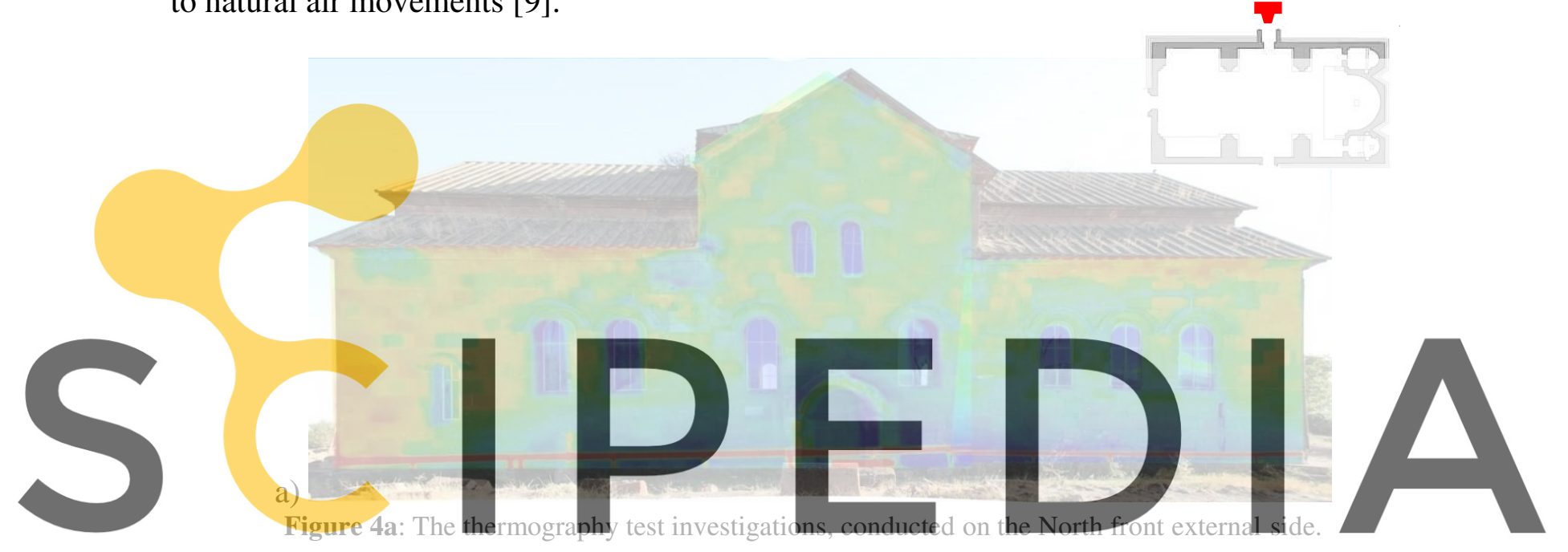

b)

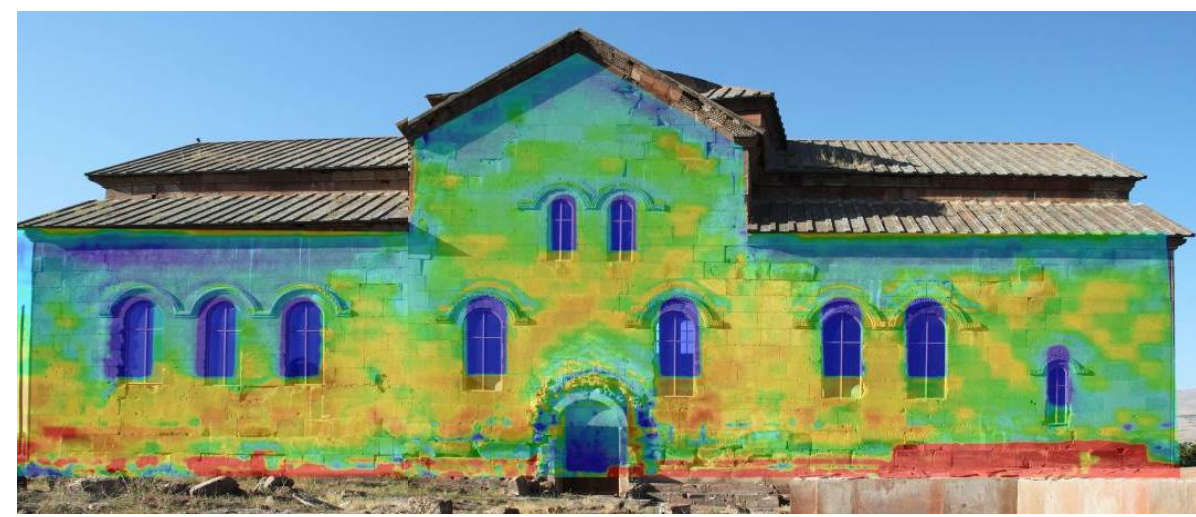

Figure 4b: The thermography test investigations, conducted on the South front external side. 


\subsection{Laboratory tests}

Samples of the materials are needed for caracterization tests. The technique of sampling is very important, since samples must be as undamaged as possible in order to be representative of the material in situ. The aims of these tests are the followings: (i) to characterise the material from a chemical, physical and mechanical point of view, (ii) to detect its origin in order to use similar materials for the repair, (iii) to know its composition and content, and (iv) to measure its decay and the durability to aggressive agents from new materials used for restoration. Since it is very difficult to sample prisms representative of the walls, only single components or small assemblages are removed [10].

The materials sampled from the walls of the Cathedral were tested in laboratory to be

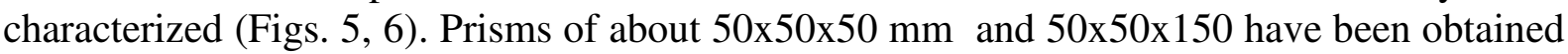
from the stone and have been subjected to two series of uniaxial compression tests, dry (Tab. 2) and wet (Tab. 3) after being characterised through ultrasonic tests (Tabs. 4-5).

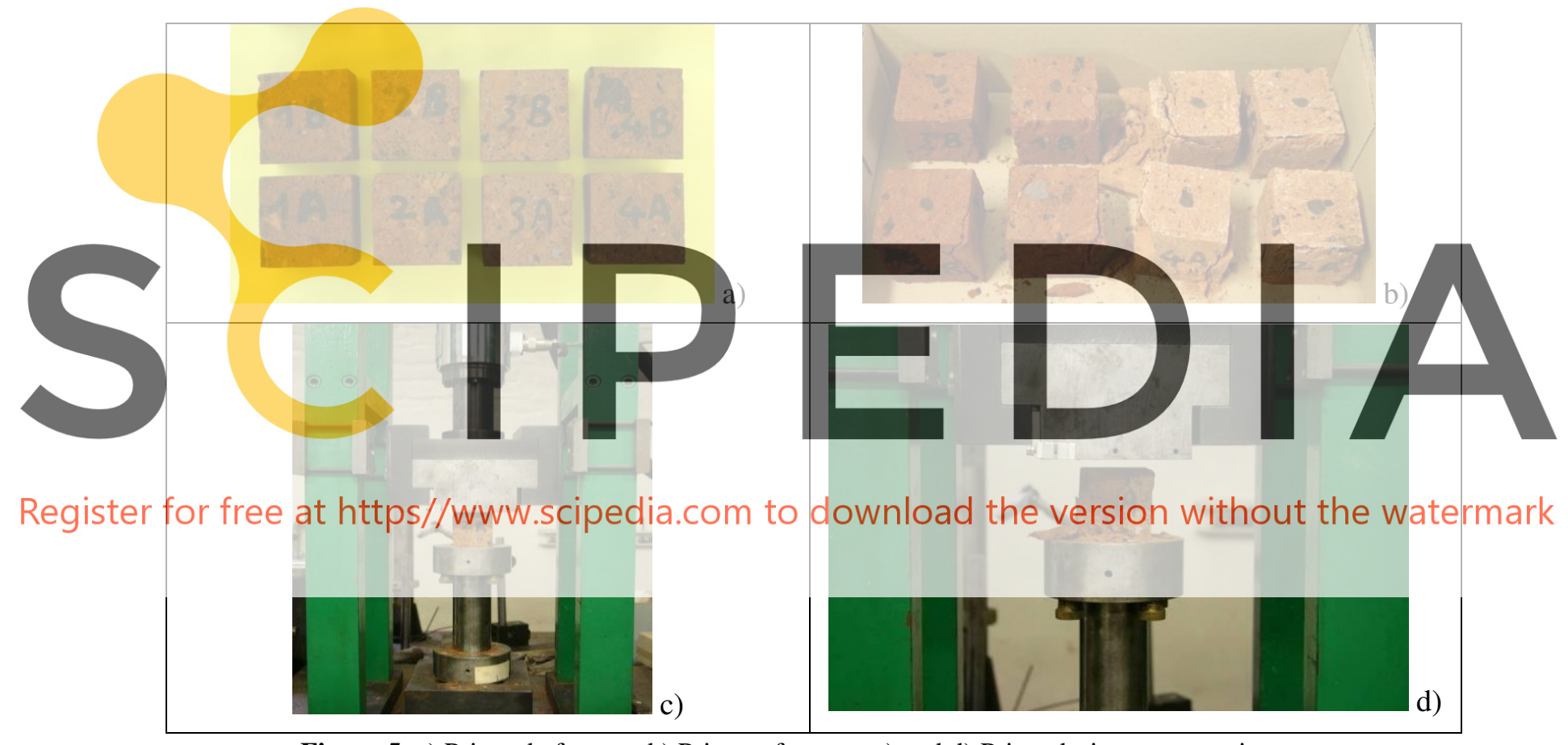

Figure 5: a) Prisms befor test; b) Prisms after test; c) and d) Prism during compressive test.

Table 2: Compression test results on specimens dried at $70^{\circ} \mathrm{C}$

\begin{tabular}{|c|c|c|c|c|c|c|c|}
\hline Name & $\begin{array}{c}\text { Length } \\
(\mathbf{m m})\end{array}$ & $\begin{array}{c}\text { Width } \\
(\mathbf{m m})\end{array}$ & $\begin{array}{c}\text { Height } \\
(\mathbf{m m})\end{array}$ & $\begin{array}{c}\text { Dry weight } \\
(\mathbf{g})\end{array}$ & $\begin{array}{c}\text { Area } \\
\left(\mathbf{m m}^{\mathbf{2}}\right)\end{array}$ & $\begin{array}{c}\text { Load } \\
(\mathbf{N})\end{array}$ & $\begin{array}{c}\sigma \mathbf{r} \\
\left(\mathbf{N} / \mathbf{m m}^{\mathbf{2}}\right)\end{array}$ \\
\hline 1-A & 51.4 & 50.7 & 50.4 & 217 & 2606 & 43772 & 16.8 \\
\hline 2-A & 48.4 & 51.8 & 50.8 & 206 & 2507 & 38259 & 15.3 \\
\hline 3-A & 48.2 & 52.1 & 50.7 & 206 & 2511 & 45940 & 18.3 \\
\hline 4-A & 51.2 & 49.5 & 50 & 207 & 2534 & 41496 & 16.4 \\
\hline \multicolumn{7}{|c|}{ Average } \\
\hline \multicolumn{7}{|c|}{ Standard deviation } \\
\hline
\end{tabular}


Table 3: Compression test results on specimens saturated with water

\begin{tabular}{|c|c|c|c|c|c|c|c|}
\hline Name & $\begin{array}{c}\text { Length } \\
(\mathbf{m m})\end{array}$ & $\begin{array}{c}\text { Width } \\
(\mathbf{m m})\end{array}$ & $\begin{array}{c}\text { Height } \\
(\mathbf{m m})\end{array}$ & $\begin{array}{c}\text { Dry weight } \\
(\mathbf{g})\end{array}$ & $\begin{array}{c}\text { Area } \\
\left(\mathbf{m m}^{\mathbf{2}}\right)\end{array}$ & Load (N) & $\begin{array}{c}\sigma \mathbf{r} \\
\left(\mathbf{N} / \mathbf{m m}^{\mathbf{2}}\right)\end{array}$ \\
\hline 1-B & 51 & 50.4 & 50.7 & 240 & 2570 & 31588 & 12.3 \\
\hline 2-B & 48.3 & 51.6 & 50.9 & 229 & 2492 & 33158 & 13.3 \\
\hline $3-\mathrm{B}$ & 48.1 & 51.2 & 50.6 & 230 & 2463 & 42968 & 17.4 \\
\hline $4-\mathrm{B}$ & 51.7 & 49.5 & 50.9 & 240 & 2559 & 34826 & 13.6 \\
\hline \multicolumn{7}{|c|}{ Average } \\
\hline \multicolumn{7}{|c|}{ Standard deviation } & $\mathbf{1 4 . 2}$ \\
\hline
\end{tabular}
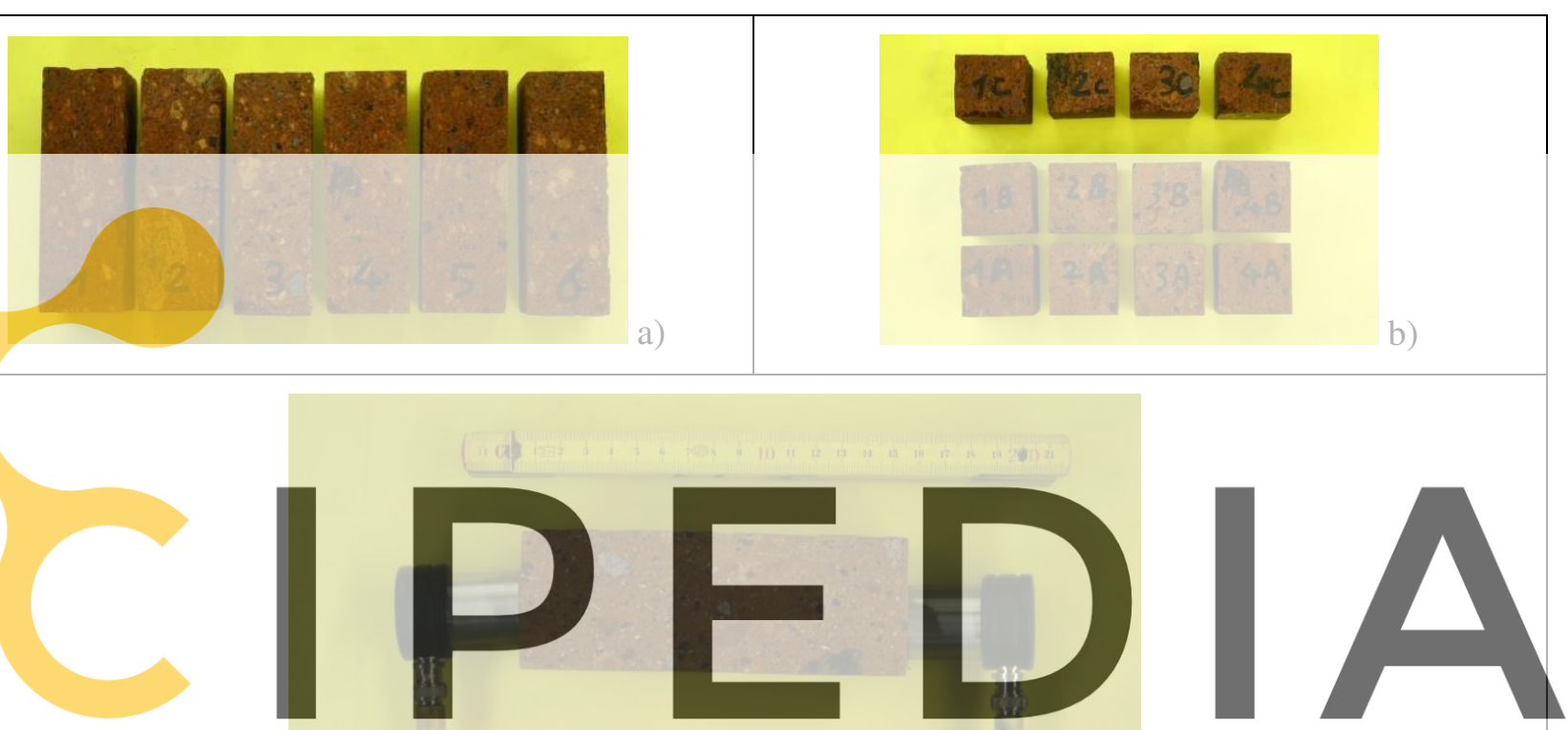

Register for free at https//www.scipedia.com to download the version without the watermark Figure 6: a) Prisms cut and rectified; b) Cubes cut and rectified; c) Prism during measurement

Table 4: Measurement of the ultrasonic velocity - UR 0\% and UR 100\%

\begin{tabular}{|c|c|c|c|c|c|}
\hline Abb. & $\begin{array}{c}\text { Length } \\
(\mathbf{m m})\end{array}$ & $\begin{array}{c}\text { UR 0\% } \\
\text { Velocity }(\mathbf{m} / \mathbf{s e c})\end{array}$ & Abb. & $\begin{array}{c}\text { Length } \\
(\mathbf{m m})\end{array}$ & $\begin{array}{c}\text { UR 100\% } \\
\text { Velocity (m/sec) }\end{array}$ \\
\hline 1-A & 50 & 2994 & $\mathbf{1 - B}$ & 50 & 2632 \\
\hline $\mathbf{2 - A}$ & 50 & 2809 & $\mathbf{2 - B}$ & 50 & 2747 \\
\hline 3-A & 50 & 2941 & $\mathbf{3 - B}$ & 50 & 2674 \\
\hline 4-A & 50 & 2924 & $\mathbf{4 - B}$ & 50 & 2703 \\
\hline $\mathbf{5}$ & 150 & 2804 & $\mathbf{6}$ & 150 & 2688 \\
\hline \multicolumn{2}{|c|}{ Average } & $\mathbf{2 8 9 4}$ & \multicolumn{2}{|c|}{ Average } & $\mathbf{2 6 6 3}$ \\
\hline \multicolumn{2}{|r|}{ Standard deviation } & $\mathbf{8 4 . 4}$ & \multicolumn{2}{|c|}{ Standard deviation } & $\mathbf{2 5 . 4}$ \\
\hline
\end{tabular}




\section{A FEW CONSIDERATIONS}

Due these investigations, both on site and in the laboratory, to some punctual inspections and to the comparison with similar cases located nearby, it has been possible to characterize the masonry by providing a hypothetical schematization of the wall section and its connection to the foundation structure. From what emerges from a preliminary analysis of the masonry, it can be assumed that the section can be defined as a three layers: two masonry facings (internal and external) and, the third one, composed by a filling in mortar and medium / large sized stones (Fig. 7). The longitudinal section of a type ashlar has an almost conical extrusion towards the inside and, thanks to this alternation, the middle layer is reduced, the internal and external facing are partially damped and the masonry acquires greater homogeneity and compactness. The masonry has a section of $90 \mathrm{~cm}$ and, at a height of about $60 \mathrm{~cm}$ from the walking surface, it progressively increases by $30 \mathrm{~cm}$ at a time until doubling thanks to a system of external steps adhered to the masonry through the filling that composes them. From a static point of view, this system recalls the structural benefits of a scarp wall (Fig. 7).

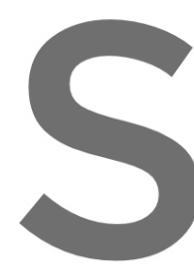

\section{Local tuff}

\section{Wrought composed by earth, lime and medium-large tuff chips (diameter 7-10 cm)}

Register for free at https//www.scipesdia.com to download the version without the watermark

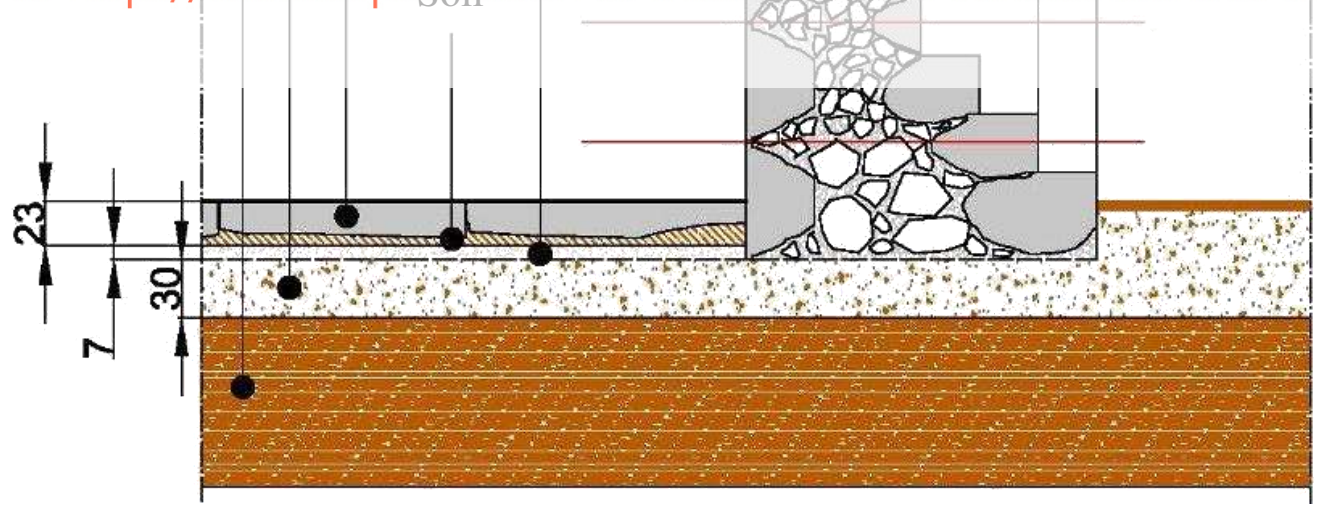

Figure 7: Hypothesis of the wall and foundation

In the case of Aruch, the stone is a tuff with chromatic variations from earth red to black, characterized by a very high porosity. The external fronts are obtained through large, wellsquared ashlars, generally arranged with alternating joints between inside and outside. From a first critical reworking of the results obtained from the sonic investigations, it was found that 
the joints of the external face are in correspondence with the center line of the internal one. This arrangement may have been specifically designed to give the masonry greater compactness in the absence of diatons (Fig. 8).
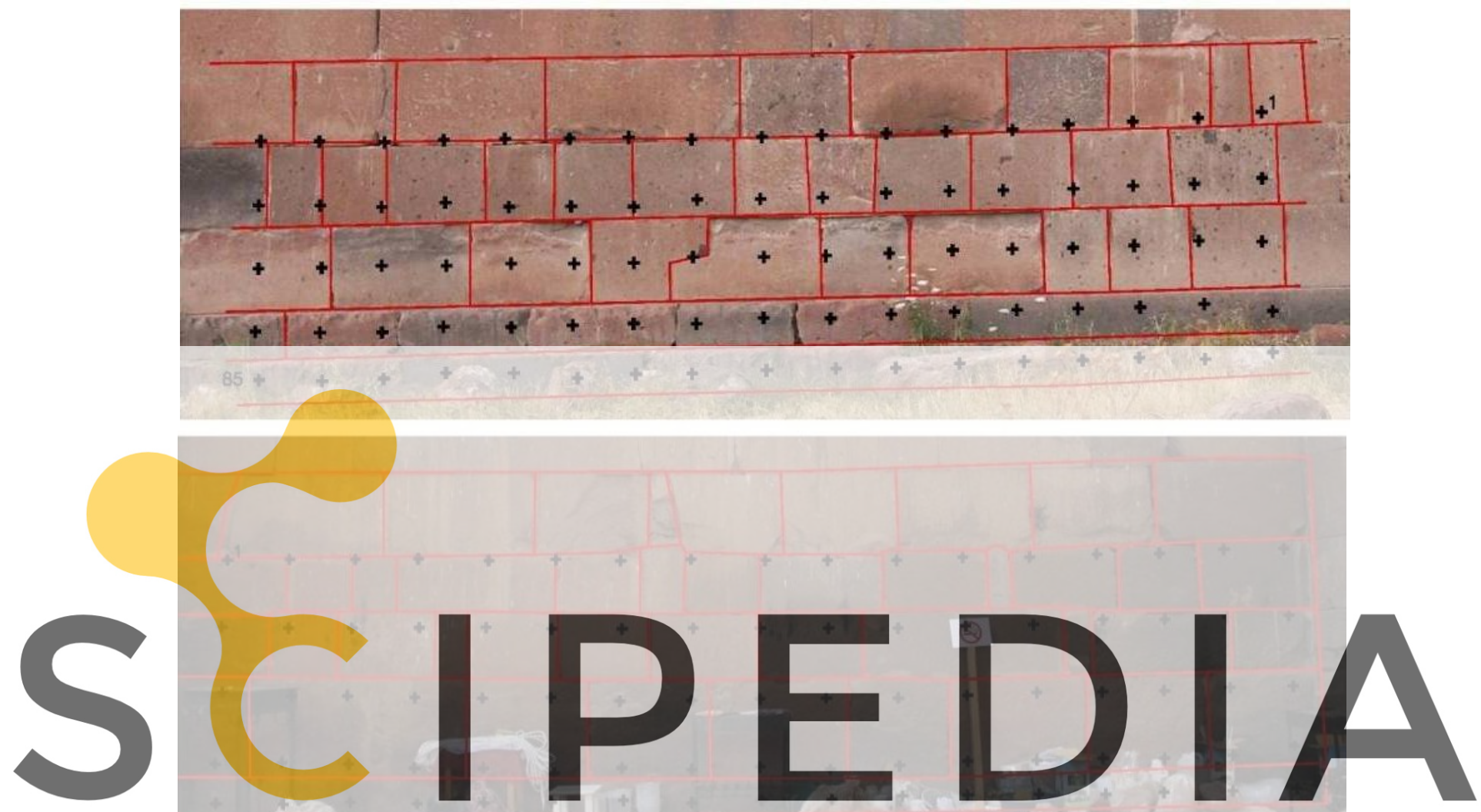

Register for free at https//www.scipedia.com to download the version without the watermark

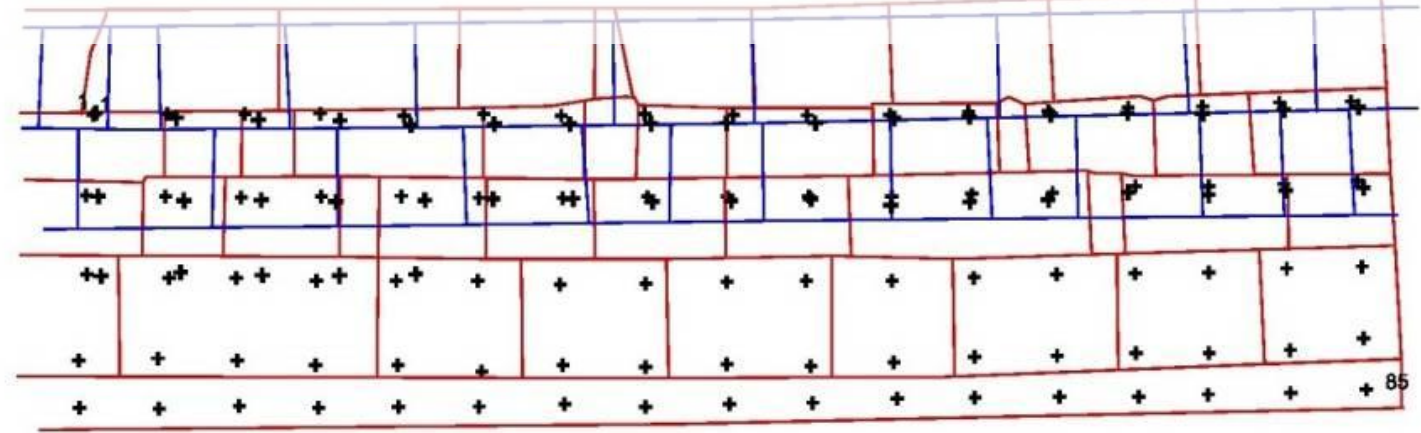

Figure 8: a) External front; b) Internal front; c) overlapping joints 


\section{CONCLUSIONS}

This brief description of available techniques and procedures illustrates the difficulty faced by the designer who must select the technically and economically correct method to define the state of preservation or damage of the structure to be restored.

The visual inspection and non-destructive techniques performed on the Cathedral of Aruch allowed to highlight the critical issues especially regarding the structural aspect. The crack pattern survey highlighted the main active kinematic mechanisms such as the rotation of the facade, the overturning of the tympanum, the thrust of the arches and vaults on the lateral structural elements and the weak connection of the main facade. The damages are due both to some original geometric imperfections and to seismic events, which have occurred in the past. In fact, Aruch is located in an area characterized by a very high seismicity.

The thermographic investigations carried out both on the south and north fronts have highlighted the presence of capillary rise and, especially in the southern prospect, a very high temperature during the recovery, this identifies an ongoing evaporative process and a wide temperature ranges, one of the main deterioration causes surveyed on these walls.

The sonic investigations carried out on the south front masonry and pillars have shown the difference density between the original materials and the new one (always stones) used for the restoration. Furthermore, the recorded data show that the pillars have a slightly dispersed sonic velocity values, this is indicative of a good state of conservation; in the masonry the results are different: the velocities are particularly low and dispersed. The lowest speeds are recorded in the south-facing walls which present the greatest deterioration on the masonry, in fact important crack patterns have been highlighted too.

The results relating to laboratory tests have shown the different compression behavior of saturated stones and dry ones. The ultrasonic speeds of the stone elements tested in the laboratory and the data recorded in situ, demonstrate the good state of conservation especially of the pillars building materials.

The test campaign extended to the whole church and the accurate crack survey allowed to design a structural monitoring [11]. In fact, a series of transducers have been installed that will allow to give a complete picture of the kinematic mechanisms in progress, as well as the possibility of evaluating a consolidation and restoration intervention [12].

\section{REFERENCES}

[1] Binda, L., The importance of investigation for the diagnosis of historic buildings: application at different scales (centers and single buildings). In: IV International seminar structural analysis of historical constructions, 10-12 November, Padova, Italy, Keynote lectures, vol 1, pp 29-42. (2004)

[2] Michael, P., Schuller, P.E., Non destructive testing and damage assessment of masonry 
structures, in NSF/ RILEM workshop: In-Situ Evaluationof Historic Wood and Masonry Structures, July 10-14, 2006 - Prague, Czech Repubblic) (2006).

[3] Binda, L., Saisi, A., Tiraboschi, C., Investigation procedures for the diagnosis of historic masonries. Constr. Build. Mater. (2000). 14(4):199-233. https://doi.org/10.1016/S09500618(00)00018-0.

[4] Casnati, G. (a cura di), The Politecnico di Milano in Armenia. An Italian Ministry of Foreign Affairs project for Restoration Training and Support to Local Institutions for the Preservation and Conservation of Ar-menian Heritage, OEMME, Venezia (2014).

[5] Cucchi, M., Tedeschi, C., Structural diagnostic, in G. Casnati (a cura di) The Politecnico di Milano in Armenia. An Italian Ministry of Foreign Affairs project for Restoration Training and Support to Local Institutions for the Preservation and Conservation of Armenian Heritage, OEMME, Venezia (2014), pp. 144-157.

[6] Binda, L., Cantini, L., Tedeschi, C., Diagnosis of Historic Masonry Structures using Non-De-scruttive Techniques. In: O. Gunes, Y. Akkaya (a cura di) Nondestructive Testing of Materials and Structures, Springer Netherlands, Dordrecht (2013), ISBN: 9789400707238, doi: 10.1007/978-94-007-0723-8_152 pp. 1089-1102 .

[7] Cantini, L., Condoleo, P., Munda, S., Tedeschi, C., Tiraboschi, C., Casarin, F., Simonato, E., Binda L. , Investigation Methodology Applied to the Structure of the Church of St. Biagio in L'Aquila. In: Nondestructive Testing of Materials and Structures. p. 1195-1201, Springer Netherlands, (2013) ISBN: 9789400707238, doi: 10.1007/978-94-007-0723$8 \_166$

[8] Binda, L. Saisi, A. Tiraboschi, C., Application of Sonic Tests to the Diagnosis of Damaged and Repaired Structures. NDT\&E International (2001) 34(2):123-138. https://doi.org/10.1016/S0963-8695(00)00037-2

[9] Binda, L., Cantini, L., Cucchi, M. Thermovision: Applications in Conservation Field to Detect Hidden Characteristics of Building Structures, in: Conference Proceedings Eleventh North American Masonry Conference (eleventh NAMC), DVD, pp. 1-11, Ed. The University of Minnesota - Twin Cities, 5-8 June 2011, Minneapolis, USA, (2011), ISBN:1-929081-39-1.

[10] Baronio, G., Binda, L., Tedeschi, C. Tiraboschi, C., Characterisation of the materials used in the construction of the Noto Cathedral. Construction and Building Materials, (2003) 17:557-571. doi:10.1016/j.conbuildmat.2003.08.007.

[11] Casarin, F., Lorenzoni, F., Islami, K., Modena, C. Dynamic identification and monitoring of the churches of St. Biagio and St. Giuseppe in L'Aquila. In Proceedings of EVACES (2011), October 3-5. Varenna, Italy.

[12] Silva, B. Pigouni, E. Valluzzi, MR. Da Porto, F., Modena, C., Assessment of the effectiveness of grout injection on the consolidation of 3-leaf stone masonry walls through the use of NDT and DT. In: Proceedings of SACH2012 structural analysis of historical constructions, Wroclaw (Poland), 15-17 October (2012), pp 1931-1939 